HUOM! Tämä on alkuperäisen artikkelin hyväksytty käsikirjoitus (AAM). Rinnakkaistallenne saattaa erota alkuperäisestä sivutukseltaan ja painoasultaan.

Käytä viittauksessa alkuperäistä lähdettä:

Hallikainen H., Aunimo L. (2020) Adoption of Digital Collaborative Networking Platforms in Companies: A Study of Twitter Usage in Finland. In: Camarinha-Matos L.M., Afsarmanesh H., Ortiz A. (eds) Boosting Collaborative Networks 4.0. PRO-VE 2020. IFIP Advances in Information and Communication Technology, vol 598. Springer, Cham. https://doi.org/10.1007/978-3-030-62412-5_8

PLEASE NOTE! This in an electronic self-archived Author accepted manuscript (AAM) version of the original article. This reprint may differ from the original in pagination and typographic detail.

Please cite the original version:

Hallikainen H., Aunimo L. (2020) Adoption of Digital Collaborative Networking Platforms in Companies: A Study of Twitter Usage in Finland. In: Camarinha-Matos L.M., Afsarmanesh H., Ortiz A. (eds) Boosting Collaborative Networks 4.0. PRO-VE 2020. IFIP Advances in Information and Communication Technology, vol 598. Springer, Cham. https://doi.org/10.1007/978-3-030-62412-5_8

The final publication is available at Springer via https://doi.org/10.1007/978-3-030-62412-5_8

$\underline{\text { Terms of reuse. }}$

(C) IFIP / Springer 2020 


\title{
Adoption of Digital Collaborative Networking Platforms in Companies: A Study of Twitter Usage in Finland
}

\author{
Heli Hallikainen ${ }^{1, *}$ and Lili Aunimo ${ }^{2}$ \\ ${ }^{1}$ University of Eastern Finland, Business School, Joensuu, Finland \\ (heli.hallikainen@uef.fi) \\ ${ }^{2}$ Haaga-Helia University of Applied Sciences, Helsinki, Finland \\ (1ili.aunimo@,haaga-helia.fi)
}

\begin{abstract}
Digital collaborative networking platforms have become increasingly important for companies. They are widely used for communication and cocreation with customers, suppliers and other actors in companies' value chains. This study takes one social media platform: Twitter, as an example of a digital collaboration platform and analyses patterns of Twitter usage among Finnish companies. The empirical part of the study is based on survey data $(n=554$ companies) and Twitter usage data of 107 of the same companies. The research data is analyzed to find the extent to which companies have adopted Twitter and for what purposes it is being used. The results of the study show that surprisingly few companies have a Twitter account and most commonly companies use Twitter to communicate about news and events to the large public. Hence, plenty of opportunities remain for taking social media platforms more efficiently in use for collaborative networking and co-creation.
\end{abstract}

Keywords: Digital collaborative networks, social media adoption, technology adoption, company segmentation, content analysis, Twitter

\section{Introduction}

For companies, digital collaborative networking platforms offer novel and efficient ways of communicating and interacting with customers, suppliers and other actors with regard customer service, product development, marketing and recruiting, among others. Collaborative networks consist of autonomous and heterogeneous entities that collaborate to achieve common or compatible goals through interaction that is made possible through computer networks [1]. Through collaborative networks, companies and their stakeholders may engage in co-creation activities that produce new value to all participants of the network. Many alternative digital collaboration platforms are available for such collaboration. Some of the platforms are used more for networking (e.g. Twitter, Facebook, LinkedIn) whereas some platforms are used more for cocreation (e.g. GitHub, Wikipedia and other open source and open media content communities). In addition to public collaborative networking platforms companies 
also use various types of internal collaborative networking platforms [2]. Internal platforms are typically available only to named actors of the network. They have been found useful e.g. in the B2M (Business to Manufacturing) setting in the context of mass customization [3]. In this study, we focus on one publicly available social media platform: Twitter, and study patterns of its use among Finnish companies. Even though Twitter may be used as a platform for collaborative networking, it may as well also be used for several other purposes.

The Internet and online based social media platforms have changed customer and company behavior by providing new ways of searching, assessing, choosing and buying [4]. For companies, social media platforms enable new possibilities for interaction and collaboration with their collaboration network, including customers, suppliers and other actors within their value chains. Customer and company-generated posts in social media represent one aspect of social media content, and overall, social media platforms provide a collaboration channel for companies. Indeed, social media platforms, including Twitter, enable the creation of virtual customer environments where online communities are formed around specific companies, brands and products [5]. Therefore, companies are increasingly placing their marketing efforts in such platforms and according to Barnes et al. [6] Twitter has proven to be a platform in which companies should focus their social media efforts.

Companies can use Twitter for various purposes and there hardly exists a "oneway-fits-all" approach in this respect. Some companies may utilize Twitter to disseminate corporate announcements [7], other companies utilize social media for employer branding [8], while some companies consider social media beneficial for employee recruitment [9]. Culnan, McHugh and Zubillaga [5] list that social media platforms may be fruitful for companies in terms of branding, e.g. in driving traffic, viral marketing, and customer loyalty and retention. Additionally, social media platforms can provide an additional channel for customer service and support and can help to gain insights in terms of company's product development $[5,10]$. These are just some examples of the numerous ways in which companies can utilize and benefit of social media data, which surely has its own challenges and pitfalls in terms of validity and representativeness [e.g. 11,12] yet such data may provide interesting insights for practitioners and academics, alike.

In this vein, the present study attempts to understand both the extent to which Twitter is being used by companies and for what purposes it is being used. Additionally, this study examines patterns of social media use within companies, attempts to discover collaborative networks related patterns and sheds light on differences between companies operating in different businesses and in different industries. Hence, the study first performs a company segmentation based on survey responses and thereafter, the study takes a detailed look on company characteristics that are associated with the identified segments. These results are then complemented by performing a content analysis on the Twitter posts issued generated by the companies that participated in the survey.

With this approach, the study contributes to the literature on technology adoption within companies, and particularly on corporate social media use as a platform for collaborative networking. The chosen approach can help other companies in positioning themselves in what comes to utilization of social media as a collaborative networking platform. Knowing where a company stands in relation to other 
companies may serve as a benchmarking tool and can provide valuable information when making strategic decisions on where to invest. As a majority of the existing research on information systems adoption relies on conventional research methods such as qualitative interviews and quantitative surveys, the present study also contributes to the academic literature by describing and applying a methodological approach that combines survey data with the objective metrics obtained from Twitter and the actual tweets issued by the companies. The latter type of data reflects a company's true activity in social media platforms.

\section{Background of the study}

Theoretical background of this study is grounded on the literature on information technology and information systems adoption within companies [e.g. 13,14,15,16] as social media use represents adoption of a novel collaboration technology. Information technologies are universally regarded essential in enhancing the competitiveness and productivity of companies [15], yet there may exist several potential paths in realizing value from such technologies. Overall, social media platforms provide an important communication channel for companies [17,18]. In addition to providing a communication and networking channel, social media platforms enable collaborative networks in companies by offering a platform for direct interaction between different stakeholders, including customers, service providers and other actors in the value chain as well as current and potential employees.

Twitter is a social media platform with a growing number of users [19] and with an increasing emphasis in professional communications [6]. However, Twitter communication sets its own challenges on the topic discovery, as tweets are short and limited to 280 characters. The global number of daily active Twitter users was 154 million users as of the fourth quarter of year 2019 [19], and this large mass of data generated by Twitter users has been considered a fruitful data source by several previous studies [20,21,22]. Grover et al. [21] sum up some of the advantages of this research approach as follows: Twitter data is freely available through the Twitter API, tweets can be analyzed objectively and the use of content analytics methods enables to classify tweets around themes and topics [21].

Freely available Twitter data may be collected for research purposes in several ways. Some researchers use the Twitter REST API in collecting tweets posted by selected Twitter accounts [20,21,23]. A limitation of this approach is that it only retrieves 3200 most recent tweets, thus creating a database with varying time periods depending on the activeness of the selected accounts. Other researchers have used the Twitter stream API to collect tweets from a certain time period [24,25]. With this approach, the dataset is narrowed down by specific query words. Some researchers use the Twitter advanced search to manually complement the dataset [20].

Some studies classify tweets into predetermined topic categories [26,27] while other studies focus on topic discovery [28]. Classification methods based on supervised machine learning have also been widely used $[29,30]$. Tweet classification is widely used when topic classes are well-known and clear-cut. Topic discovery from 
Twitter data, on the other hand, is used when no previous knowledge exists of the topic classes or when those classes may change over time [30]. Topic discovery methods may be categorized as distance-based and probabilistic methods [31]. Probabilistic models typically consider a tweet as a mixture of topics. Latent Dirichlet Allocation (LDA) [32] is a well-known example of such a probabilistic model. It is a method that is commonly used to model the topics within a collection of natural language documents.

\section{Methodology}

\subsection{Data collection and sample}

The study uses a combination of survey data $(n=554)$ and Twitter data generated by the companies that participated in the survey. Survey data was collected using an online questionnaire sent out to companies operating in Finland, and data collection resulted in 554 valid responses. In the questionnaire, respondents were asked to indicate the extent to which their company utilized the so-called big data in their business on a Likert scale ranging from $1=$ little or no use to $5=$ heavy use. Additionally, the respondents were asked some background questions about the characteristics of the companies they represent. Majority of the respondents represented small $(n=378)$ and medium-sized $(n=133)$ companies, and 417 operated in B2B markets, in comparison to B2C markets $(n=137)$.

Additionally, a large database of approximately 15 million tweets was constructed using the Stream API provided by Twitter and by collecting all tweets between December 2018 and May 2019 where the language of the Twitter account was set to Finnish. This data was used to extract the tweets posted by those 554 companies that participated in the survey. This analysis revealed that only 107 of the participating companies had an active Twitter account, and hence the Twitter dataset used in this study consists of 16,801 tweets posted by 107 companies during a six-month period between December 2018 and May 2019. The information on the status (number of tweets posted from the account since its creation), followers, friends and favorites were retrieved using the Twitter API.

\subsection{K means cluster analysis}

Data analysis was performed in several steps. First, using k means cluster analysis, the data was grouped into segments based on the survey responses on how companies reported to use big data in their business. $\mathrm{K}$ means cluster analysis does not permit a mathematical demonstration of an optimal solution for the number of clusters, and therefore we started the data analysis by comparing some alternative cluster solutions. A comparison of three-, four-, five- and six-cluster solutions shows that a five-cluster solution appears the most optimal, because a solution with six clusters produced two very similar middle segments. Three- and four-cluster solutions, on the other hand, identified the utmost segments but did not show that much variation between the 
middle segments. Hence, the study considered a five-cluster solution the most optimal and subsequent analyses examine patterns of Twitter use among the identified five segments with n 205, 71, 96, 55 and 127 for segments 1-5, respectively.

\subsection{Twitter content analysis}

Based on the collected Twitter data, two types of data analysis were performed: 1) an overall analysis of the Twitter activity and 2) an analysis on the content of the tweets posted by the companies. Twitter activity was measured using the following indicators: statuses (number of tweets posted so far), followers (number of followers), friends (number of Twitter accounts followed by the company) and favorites (number of likes the company has created for the tweets of other Twitter users). Specifically, tweets were modelled and analyzed using Latent Dirichlet Allocation (LDA), which is "a generative probabilistic model for collections of discrete data, such as text corpora" [32, p. 993]. In this study LDA is applied on Twitter tweets, and each tweet is considered a mixture of a small number of topics and that each word's presence is attributable to one of the tweet's topics [31].

The LDA method was chosen because topic contents were not known beforehand and because LDA is commonly used to model topics in similar cases [31]. In this study, the researchers experimented with different numbers of topic categories and found out that in this study, tweets were most naturally divided into five different topic categories. Data analysis was performed using KNIME [33], with Newman et al.'s [34] and Yao, Mimno and McCallum's [35] implementations of the core algorithms. The implementation uses the "MALLET: A Machine Learning for Language Toolkit" topic modeling library [36].

\section{Results}

\subsection{Segmentation results}

Using ANOVA in SPSS 25, we first looked at the characteristics of the identified segments in order to understand underlying factors that might shed light on some of the key differences between the segments derived using survey data and $\mathrm{k}$ means cluster analysis. Additionally, we looked at the Twitter activity of the identified segments to understand patterns of Twitter behavior by the companies. Surprisingly, only 107 companies had an active Twitter account, and we extracted the Tweets posted by these companies during a six-months' period ranging from December 2018 to May 2019. Results of this comparison shows that the difference in Twitter activity is not statistically significant, however, segment 3 is the most active user of Twitter in terms of status posts, followed by segments $2,4,1$ and 5 , respectively (Table 1 ). 
Segment 1 consists of mainly smaller companies, the average number of employees being 50 and the smallest among the identified segments. Companies of this segment operate mainly in manufacturing and construction sectors. Companies in this segment are relatively passive in using Twitter and hence do not seem to be at the frontline in adopting information technologies.

Segment 2 is the second smallest in term of the number of employees, with the average number of employees being 90. Construction companies and companies providing professional, scientific, and technical services are the two largest industry sectors. Based on Twitter metrics, this segment has more Twitter status updates, followers, friends and favorites, compared to other segments.

Segment 3 represents larger companies with an average of 214 employees, the largest industry sector being manufacturing companies, followed by wholesale and retail trade. With regard the use of Twitter, companies in segment 3 rank as the most active in posting tweets themselves but have a relatively low number of followers and friends in Twitter.

Segment 4 is mainly representative of manufacturing companies, followed by construction companies and companies providing real estate services. The average of company size is the largest, the average number being 405 employees. Based on Twitter metrics, companies in segment 4 are quite passive in using Twitter and have less followers and friends, compared to the average.

Segment 5 represents medium-sized companies, the average of company size being 194 employees. The largest representative industries in segment 5 are manufacturing companies, wholesale and retail trade, and construction companies. Overall, companies in this segment are not very active users of Twitter.

\begin{tabular}{|c|c|c|c|c|c|c|}
\hline & $\begin{array}{l}\text { Segment } \\
\begin{array}{l}1 \\
N=25\end{array} \\
\end{array}$ & $\begin{array}{c}\text { Segment } \\
2 \\
N=23 \\
\end{array}$ & $\begin{array}{c}\text { Segment } \\
3 \\
\mathrm{~N}=\mathbf{2 4} \\
\end{array}$ & $\begin{array}{c}\text { Segment } \\
4 \\
N=14 \\
\end{array}$ & $\begin{array}{c}\text { Segment } \\
5 \\
N=21 \\
\end{array}$ & $F(p)$ \\
\hline Statuses & 1230 & 3284 & 3781 & 1402 & 1134 & $\begin{array}{l}0.855 \\
(0.494)\end{array}$ \\
\hline Followers & 1189 & 3089 & 1706 & 739 & 1795 & $\begin{array}{l}0.848 \\
(0.498) \\
\end{array}$ \\
\hline Friends & 562 & 2056 & 429 & 129 & 269 & $\begin{array}{l}1.066 \\
(0.377)\end{array}$ \\
\hline Favorites & 914 & 1237 & 667 & 288 & 611 & $\begin{array}{l}0.944 \\
(0.442) \\
\end{array}$ \\
\hline
\end{tabular}

Table 1. The Twitter activity of the companies per segment. Values represent mean numbers of statuses, followers, friends and favorites by the companies belonging to a specific segment.

\subsection{Twitter content analysis}

Next, we analyzed the Twitter activity of the companies based on the tweet dataset consisting of tweets from December 2018 to May 2019. Table 2 shows first the total number of tweets per segment, followed by the difference from the expected number of tweets in parenthesis. The expected number of tweets is calculated by multiplying 
the total number of tweets by the proportion of companies belonging to the segment. The difference is calculated as the frequency - expected. A negative value signifies that the companies in a specific segment tweet less than expected and a positive value means that there are more tweets than expected. Table 2 shows that companies belonging to segments 2 and 3 are unexpectedly active in posting tweets. To compare, companies in segments 1,4 and 5 are unexpectedly inactive in posting tweets.

\begin{tabular}{|l|c|c|c|c|c|}
\hline & $\begin{array}{c}\text { Segment 1 } \\
(\mathbf{n}=\mathbf{2 5})\end{array}$ & $\begin{array}{c}\text { Segment 2 } \\
(\mathbf{n}=\mathbf{2 3})\end{array}$ & $\begin{array}{c}\text { Segment 3 } \\
(\mathbf{n}=\mathbf{2 4})\end{array}$ & $\begin{array}{c}\text { Segment 4 } \\
(\mathbf{n}=\mathbf{1 4})\end{array}$ & $\begin{array}{c}\text { Segment 5 } \\
(\mathbf{n}=\mathbf{2 1})\end{array}$ \\
\hline $\begin{array}{l}\text { Total no of } \\
\text { tweets }\end{array}$ & 2836 & 4226 & $5666(1896)$ & 1296 & 2777 \\
$12 / 2018-$ & $(-1089)$ & $(615)$ & & $(-902)$ & $(-520)$ \\
$05 / 2019$ & & & & & \\
\hline
\end{tabular}

Table 2. The total number of tweets posted by the segment. Difference from the expected value is reported inside parenthesis.

We took an effort to understand the purposes for which the identified segments mainly created content in Twitter. Using data obtained from Twitter and LDA method, five topic categories were identified from the Twitter data $(n=16,801)$. Specifically, five distinct topic categories were identified based on terms occurring in the tweets (Table 3 ).

\begin{tabular}{|l|l|l|}
\hline Topic & Main terms occurring in tweets & N (\%) \\
\hline $\begin{array}{l}\text { National communications, } \\
\text { general societal issues } \\
\text { concerning the entire } \\
\text { country }\end{array}$ & $\begin{array}{l}\text { Equality, sustainable development, } \\
\text { accessibility, elections }\end{array}$ & $3069(18 \%)$ \\
\hline $\begin{array}{l}\text { Local news related } \\
\text { communications }\end{array}$ & $\begin{array}{l}\text { Location names, vehicle, security, } \\
\text { news, driver }\end{array}$ & $4167(25 \%)$ \\
\hline $\begin{array}{l}\text { Marketing, events such as } \\
\text { sports events }\end{array}$ & $\begin{array}{l}\text { League, welcome, company names } \\
\text { and places }\end{array}$ & $3393(20 \%)$ \\
\hline $\begin{array}{l}\text { Local events related } \\
\text { communications, } \\
\text { especially local events } \\
\text { and facts }\end{array}$ & $\begin{array}{l}\text { Cities, health services, customer, } \\
\text { services }\end{array}$ & $3030(18 \%)$ \\
\hline $\begin{array}{l}\text { Recruitment of personnel } \\
\text { Recruitment, position, application, } \\
\text { task, company, service, euro }\end{array}$ & $3142(19 \%)$ \\
\hline
\end{tabular}

Table 3. Topic categories identified using LDA. The terms have been translated from Finnish language.

Chi-square test shows that the differences between segments and topics of the tweets is statistically significant ( $\mathrm{df}=16$, sum of squared errors $=2054,399$ and the $\mathrm{p}$ value $<0,001)$. Using cross-tabulation, we took a deeper look at the activity of the companies belonging to identified segments in posting different types of content in Twitter (Table 4). Table 4 shows the absolute numbers of tweets per topic produced 
by companies in each segment. The figures in parenthesis shows the deviation from the expected number of tweets. The expected frequencies of tweets are calculated as the probability of the topic in the tweet dataset multiplied by the number of tweets in the segment. The deviation is calculated simply as the frequency - expected. A negative value signifies that the companies belonging to the segment tweet about a particular topic category less than expected and a positive value means that there are more tweets about a topic category than expected.

Based on the results (Table 4), companies in segment 1 are the most active in tweeting about topics that relate to national communications, and less active in tweeting about other identified topic categories. Segment 2 posts less about local news, but more than expected about national communications, marketing, local events and recruitment related topics. Segment 3 is the most active in tweets that relate to local news and marketing topics, while segment 4 shows activity particularly in posting about local events and recruitment related topics. Alike segment 4, segment 5 similarly posts more tweets than expected about local events and recruitment related topics, but also about marketing related topics.

\begin{tabular}{|l|l|l|l|l|l|}
\hline & $\begin{array}{l}\text { Segment 1 } \\
(\mathbf{n}=25)\end{array}$ & $\begin{array}{l}\text { Segment 2 } \\
(\mathbf{n}=23)\end{array}$ & $\begin{array}{l}\text { Segment 3 } \\
(\mathbf{n}=24)\end{array}$ & $\begin{array}{l}\text { Segment 4 } \\
(\mathbf{n}=14)\end{array}$ & $\begin{array}{l}\text { Segment 5 } \\
(\mathbf{n}=21)\end{array}$ \\
\hline $\begin{array}{l}\text { National } \\
\text { communications } \\
(\mathrm{n}=3069)\end{array}$ & $1015(497)$ & $802(30)$ & $664(-371)$ & $161(-76)$ & $427(-80)$ \\
\hline $\begin{array}{l}\text { Local news } \\
(\mathrm{n}=4167)\end{array}$ & $429(-274)$ & $848(-200)$ & $2221(816)$ & $133(-188)$ & $536(-153)$ \\
\hline $\begin{array}{l}\text { Marketing } \\
(\mathrm{n}=3393)\end{array}$ & $461(-112)$ & $943(90)$ & $1255(111)$ & $157(-105)$ & $577(16)$ \\
\hline $\begin{array}{l}\text { Local events } \\
(\mathrm{n}=3030)\end{array}$ & $423(-88)$ & $820(58)$ & $759(-263)$ & $485(251)$ & $543(42)$ \\
\hline $\begin{array}{l}\text { Recruitment } \\
(\mathrm{n}=3142)\end{array}$ & $508(-22)$ & $813(23)$ & $767(-293)$ & $360(118)$ & $694(175)$ \\
\hline
\end{tabular}

Table 4. Cross tabulation of identified segments and main topic categories (Note: White cells indicate a deviation less than 100, light grey cells a deviation between 100-300 and dark grey cell have a deviation greater than 300 .)

\section{Discussion}

The study contributes to the literature on technology adoption within companies, and particularly on corporate social media adoption literature by examining the extent to which companies use Twitter, and for which purposes it is being used. Specifically, the study identified segments based on how companies reported to use data in their business, after which the study examined how the identified segments differed in terms of company's background characteristics and patterns of utilizing Twitter. 
Results of the study show that identified segments differ in their background characteristics and patterns of utilizing Twitter. As such, this study provides empirical results for practitioners and academics alike, and results of this study can serve as a benchmarking tool in helping companies to position themselves what comes to utilization of social media as a platform for collaboration in their networks.

The topic discovery performed on the tweets show that out of the six dimensions of collaboration characterizing collaborative networks and industry 4.0, [37], the dimension 2: Horizontal integration through global value chain networks is the most dominant among the companies of the study. This dimension involves networking along the entire value chain, including customers, suppliers, and business partners. The topics discovered are strongly related to communications, information sharing aiming at collaboration and marketing that is aimed at customers and especially consumer customers. There is plenty of unused potential for collaborative networking with other stakeholders of the value chain. The results of the content analysis on companies' tweets show surprisingly few tweets that illustrate the dimension 6: New business models and customer access [37] of collaborative networks and industry 4.0. This dimension includes tweets between the company and empowered customers, and they are related to co-design, co-creation, and customer experience, among others.

Interestingly, results of this study show that the representative sample, i.e. medium and large-sized companies operating in Finland, are less active in utilizing Twitter compared to what was expected based on some recent reports and studies [6]. In the present study, approximately 20 percent of the companies were active in utilizing Twitter while e.g. Barnes, Mazzola and Killeen [6] reported that 96 percent of Fortune500 companies were present in Twitter. The difference may relate to the fact that in the present study, majority of the companies operated in B2B markets, in comparison to $\mathrm{B} 2 \mathrm{C}$ markets, and companies in B2C sector typically acknowledge benefits of new technologies faster, compared to B2B sector [38]. On the other hand, it is likely that Fortune500 companies, in general, have more visibility in social media platforms, compared to small- and medium-sized companies, of which many are less well-known. Results of this study are in line with a recent study conducted in Finland [13] which reported that among Finnish companies, 53 percent had adopted at least one of the following social media platforms: Facebook, Instagram, LinkedIn, Pinterest, Periscope, Twitter, or Vimeo. More specifically, Koski et al. [13] reported that 20 percent of Finnish companies were involved in Twitter, but Twitter was only the fourth social media platform in popularity after Facebook, Youtube and Instagram. Hence, Twitter might not be the number one social media platform from the viewpoint of Finnish companies, while prior research indeed reports that Twitter use has several benefits, including building of company image and brand, coinnovation with customers, and potential in recruiting employees [13].

With regard the identified Twitter topic categories, the categories discovered by the LDA method are somewhat different from those expected. A tweet category that that seems to be missing is "customer care" types of tweets which are typical in Twitter for companies such as airlines and other consumer service providers. This finding may relate to the fact that majority of the companies in the present study were primarily business-to-business companies. Also, tweets concerning corporate finance, and corporate policies regarding topics such as sustainability, did not form a separate 
group in the study. This may relate to a low number of publicly listed companies in the dataset as well as to the fact that publicly listed companies are often multinational, and hence, their tweets are typically posted from the parent organization's Twitter account and possibly in other language than Finnish. It is also noteworthy that such tweets are commonly posted through the company CEO's Twitter account [21], which this study did not control for.

\section{Limitation and future research}

This study is bound by limitations that provide suggestions for future research. We consider the combined use of survey data and Twitter metrics a strength of this study, however, it is noteworthy that data for the study was collected among Finnish companies, and hence, future studies are encouraged to use a similar research approach to extend these findings to other countries and organizational cultures. We believe that these results may be generalizable to other developed and digitally advanced countries as Finland ranks first among the 29 European Union countries in the Digital Economy and Society Index [39]. On the other hand, it is noteworthy that the Finnish population and Finnish companies, in general, are not as active in using Twitter as some other countries [13].

Also, the chosen research methods require some consideration. The use of Twitter data is also bound by some limitations, which are noted e.g. by Hino and Fahey [23]. The tweet database was constructed using the Stream API provided by Twitter, which has been shown to provide a biased sample [40]. However, as long as the number of retrieved tweets does not exceed 1 percent of the total volume of Twitter traffic, Twitter documentation suggests that all tweets are retrieved [40]. A relatively large volume of tweets was retrieved for the study, and the search query was set to retrieve posts that were issued by a Twitter account that had Finnish set as language. Some Twitter accounts may have an erroneous language code and tweets posted from such accounts were not included in the present dataset.

It is noteworthy that in the collected dataset, a relatively large number of tweets were issued by a few operators such as newspapers, event organizers and public organizations. This means that many of the tweets included posts about contemporary topics and news events, or announcements of forthcoming events, including e.g. music concerts and sports events. On the other hand, other types of operators, such as B2B companies, typically issue a much smaller number of tweets. Future research should evaluate whether having a more balanced tweet dataset would enable the LDA algorithm to identify more fine-grained social media platform usage patterns shortness is one of the key characteristics of tweets, and in general, topic detection among tweets can be challenging [31]. Thus, techniques such as metadata enrichment, network structure of actors and enriching the tweets with term expansion techniques [41] should be experimented within future work on tweet topic discovery of company tweets.

Future research on collaborative networks in Twitter should better consider the network structure of Twitter data. The present study analyzed the Tweets of companies that had participated in the survey from the point of view of collaborative 
networking and its various dimensions. Future research should also analyze the retweets, replies and links between tweets issued by other actors in the network. The networking behavior of all actors of each company's value chain should be studied based on Twitter data. This would shed more light on which of the dimensions of collaborative networks or industrie 4.0 are present - and to what extant - in the Twitter behavior of companies.

\section{Conclusions}

This study sheds light on how widely Twitter is used by Finnish companies, Twitter representing an example of a collaborative networking platform for companies. To form a deeper understanding on how companies utilized Twitter for different purposes, the study used a combination of survey data $(n=554)$ and Twitter data generated by the companies that participated in the survey. In this study, Twitter user data and the tweets generated by the companies were examined. The content analysis is done with the LDA algorithm and it is based on Twitter data collected during a six-month period between December 2018 and May 2019.

Surprisingly, it turned out that only 107 of the 554 companies had an active Twitter account, and hence, companies in this study were less active in Twitter than expected. Interestingly, the identified segments differed in the extent to which they share content and follow others in Twitter. Specifically, segments 2 and 3, i.e. the relatively small companies from e.g. construction, manufacturing and retail sectors, were the most active in utilizing Twitter in content sharing and networking. The LDA-based content analysis reveals that most commonly companies use Twitter to communicate about news and events to the large public, followed by marketing and recruiting related content. Overall, the companies in Finland use social media less than expected and those that use it, prefer to use it for very traditional purposes, such as communications to the wide public. Hence, the present study shows that plenty of opportunities remain for taking social media platforms, such as Twitter, more efficiently into use for collaborative networking and co-creation. 


\section{References}

1. Camarinha-Matos, L.M., Hamideh A. "Collaborative Networks: A New Scientific Discipline,” Journal of Intelligent Manufacturing 16(4-5), pp. 439-452. (2005)

2. Ferron, M., Massa, P., Odella, F. "Analyzing Collaborative Networks Emerging in Enterprise 2.0: The Taolin Platform. Procedia-Social and Behavioral Sciences, 10, 68-78. (2011)

3. Mourtzis, D. "Internet Based Collaboration in the Manufacturing Supply Chain," CIRP Journal of Manufacturing Science and Technology, 4(3), pp. 296-304. (2016)

4. Alves, H., Fernandes, C.,Raposo, M. "Social Media Marketing: A Literature Review and Implications," Psychology \& Marketing, 33(12), 1029-1038. (2016)

5. Culnan, M. J., McHugh, P. J., Zubillaga, J. I.. "How Large US Companies Can Use Twitter and Other Social Media to Gain Business Value," MIS Quarterly Executive (9:4), pp. 243259. (2010)

6. Barnes, N. G., Mazzola, A., Killeen, M. "Oversaturation \& Disengagement: The 2019 Fortune 500 Social Media Dance," Center for Marketing Research of the University of Massachusetts Dartmouth, January 9. https://www.umassd.edu/cmr/research/social-mediaresearch/2019-fortune-500.html, accessed February 7, 2020. (2020)

7. Prokofieva, M. "Twitter-Based Dissemination of Corporate Disclosure and the Intervening Effects of Firms' Visibility: Evidence from Australian-Listed Companies," Journal of Information Systems (29:2), pp. 107-136. (2015)

8. Roper, S., de Carvalho, L. V., Guzman, F., Sivertzen, A. M., Nilsen, E. R., Olafsen, A. H. "Employer Branding: Employer Attractiveness and the Use of Social Media," Journal of Product \& Brand Management (22:7), pp 473-483. (2013)

9. El Ouirdi, M., El Ouirdi, A., Segers, J., Pais, I. "Technology Adoption in Employee Recruitment: The Case of Social Media in Central and Eastern Europe," Computers in Human Behavior (57), pp. 240-249. (2016)

10. Martin-Domingo, L., Martín, J. C., Mandsberg, G. "Social Media as a Resource for Sentiment Analysis of Airport Service Quality (ASQ)," Journal of Air Transport Management (78), pp. 106-115. (2019)

11. Stieglitz, S., Mirbabaie, M., Ross, B., Neuberger, C. "Social Media Analytics - Challenges in Topic Discovery, Data Collection, and Data Preparation," International Journal of Information Management (39), pp. 156-168. (2018)

12. Tufekci, Z. "Big Questions for Social Media Big Data: Representativeness, Validity and Other Methodological Pitfalls," In Eighth International AAAI Conference on Weblogs and Social Media. (2014)

13. Koski, H., Pajarinen, M., Rouvinen, P. "What Company Characteristics are Associated with the Adoption of Social Media?," Industry and Innovation (26:8), pp. 880-897. (2019)

14. Melville, N., Kraemer, K., Gurbaxani, V. "Information Technology and Organizational Performance: An Integrative Model of IT Business Value," MIS Quarterly (28:2), pp. 283322. (2004)

15. Oliveira, T., Martins, M. F. "Literature Review of Information Technology Adoption Models at Firm Level," Electronic Journal of Information Systems Evaluation (14:1), pp. 110-121. (2011)

16. Siamagka, N. T., Christodoulides, G., Michaelidou, N., Valvi, A. "Determinants of social media adoption by B2B organizations," Industrial Marketing Management (51), pp. 89-99. (2015)

17. Cheng, X., Fu, S., de Vreede, G. J. "Understanding Trust Influencing Factors in Social Media Communication: A Qualitative Study," International Journal of Information Management (37:2), pp. 25-35. (2017) 
18. Floreddu, P. B., Cabiddu, F. "Social Media Communication Strategies," Journal of Services Marketing (30:5), pp. 490-503. (2016)

19. Statista. Leading countries based on number of Twitter users as of January 2020. https://www.statista.com/statistics/242606/number-ofactive-twitter-users-in-selectedcountries/, accessed February 7, 2020. (2019)

20. Albarrak, M. S., Elnahass, M., Papagiannidis, S., Salama, A. "The Effect of Twitter Dissemination on Cost of Equity: A Big Data Approach," International Journal of Information Management (50), pp. 1-16. (2020)

21. Grover, P., Kar, A. K., and Ilavarasan, P. V. "Impact of Corporate Social Responsibility on Reputation - Insights from Tweets on Sustainable Development Goals by CEOs," International Journal of Information Management (48), pp. 39-52. (2019)

22. Ren, Y., Wang, R., Ji, D. "A Topic-Enhanced Word Embedding for Twitter Sentiment Classification," Information Sciences (369), pp. 188-198. (2016)

23. Hino, A., Fahey, R. A. "Representing the Twittersphere: Archiving a Representative Sample of Twitter Data under Resource Constraints," International Journal of Information Management (48), pp. 175-184. (2016)

24. Milajevs, D. "Retrieval of Visually Shared News," In Conference on Artificial Intelligence and Natural Language, pp. 59-73. (2019)

25. Xu, W. W., Chiu, I. H., Chen, Y., Mukherjee, T. "Twitter Hashtags for Health: Applying Network and Content Analyses to Understand the Health Knowledge Sharing in a TwitterBased Community of Practice," Quality \& Quantity (49:4), pp. 1361-1380. (2015)

26. Lin, J. S., Peña, J. "Are You Following Me? A Content Analysis of TV Networks' Brand Communication on Twitter" Journal of Interactive Advertising (12:1), pp. 17-29. (2011)

27. Parganas, P., Anagnostopoulos, C., Chadwick, S. "'You'll Never Tweet Alone': Managing Sports Brands through Social Media" Journal of Brand Management (22:7), 551-568. (2015)

28. Vicient, C., Moreno, A. "Unsupervised Topic Discovery in Micro-Blogging Networks," Expert Systems with Applications (42:17-18), pp. 6472-6485. (2015)

29. Ghiassi, M., Lee, S. "A Domain Transferable Lexicon Set for Twitter Sentiment Analysis Using a Supervised Machine Learning Approach," Expert Systems with Applications (106), pp. 197-216. (2018)

30. Missier, P., Romanovsky, A., Miu, T., Pal, A., Daniilakis, M., Garcia, A., Cedrim, D., and da Silva Sousa, L. "Tracking Dengue Epidemics Using Twitter Content Classification and Topic Modelling," In International Conference on Web Engineering, pp. 80-92. (2016)

31. Chinnov, A., Kerschke, P., Meske, C., Stieglitz, S., Trautmann, H. "An Overview of Topic Discovery in Twitter Communication through Social Media Analytics," in Twenty-first Americas Conference on Information Systems. (2015)

32. Blei, D. M., Ng, A. Y., Jordan, M. I. 2003. "Latent Dirichlet Allocation," Journal of Machine Learning Research (3), pp. 993-1022.

33. Berthold, M. R., Cebron, N., Dill, F., Gabriel, T. R., Kötter, T., Meinl, T., Ohl, P., Thiel, K., Wiswedel, B. "KNIME - The Konstanz Information Miner: Version 2.0 and Beyond," ACM SIGKDD Explorations Newsletter (11:1), pp. 26-31. (2009)

34. Newman, D., Asuncion, A., Smyth, P., Welling, M. "Distributed Algorithms for Topic Models," Journal of Machine Learning Research (10), pp. 1801-1828. (2009)

35. Yao, L., Mimno, D., McCallum, A. "Efficient Methods for Topic Model Inference on Streaming Document Collections," In Proceedings of the 15th ACM SIGKDD International Conference on Knowledge Discovery and Data Mining, pp. 937-946. (2009)

36. McCallum, A. K. "MALLET: Machine Learning for Language Toolkit," http://mallet.cs.umass.edu, accessed June 18, 2019. (2002) 
37. Camarinha-Matos, L. M., Fornasiero, R., \& Afsarmanesh, H. "Collaborative Networks as a Core Enabler of Industry 4.0," In Working Conference on Virtual Enterprises, pp. 3-17. Springer, Cham. (2017)

38. Lacka, E., Chong, A. "Usability Perspective on Social Media Sites' Adoption in the B2B Context," Industrial Marketing Management (54), pp. 80-91. (2016)

39. European Commission. "The Digital Economy and Society Index,", https://ec.europa.eu/digital-single-market/en/digital-economy-and-society-index-desi, accessed January 31, 2020. (2016)

40. Tromble, R., Storz, A., Stockmann, D. “We Don't Know What We Don't Know: When and How the Use of Twitter's Public APIs Biases Scientific Inference," (SSRN Scholarly Paper No. ID 3079927). Rochester, NY: Social Science Research Network. (2017)

41. Perez-Tellez, F., Pinto, D., Cardiff, J., Rosso, P. "On the Difficulty of Clustering Company Tweets," In Proceedings of the 2nd international workshop on Search and mining usergenerated contents (pp. 95-102). (2010) 